\title{
Effectiveness of different footbathing frequencies using copper sulfate in the control of digital dermatitis in dairy cows
}

\author{
M. H. M. Speijers, ${ }^{1}$ G. A. Finney, ${ }^{\star}$ J. McBride, ${ }^{\star}$ S. Watson, $†$ D. N. Logue, $\neq$ and N. E. O’Connell§ \\ *Agri-Food and Biosciences Institute (AFBI), Agriculture Branch, Large Park, Hillsborough, Co. Down, BT26 6DR, United Kingdom \\ †Agri-Food and Biosciences Institute, Biometrics Department, Newforge Lane, Belfast, BT9 5PX, United Kingdom \\ $\ddagger$ Faculty of Veterinary Medicine, University of Glasgow, 464 Bearsden Road, Glasgow, UK, G61 1QH \\ $\S S c h o o l$ of Biological Sciences, Medical Biology Centre, Queens University Belfast, 97 Lisburn Road, Belfast, BT9 7BL, United Kingdom
}

\section{ABSTRACT}

Two experiments were conducted to test the effectiveness of different footbathing frequencies using $\mathrm{CuSO}_{4}$ in the control of digital dermatitis (DD) in groups of dairy cows with low and high DD prevalence in an endemically infected herd. During the study, groups of cows walked through allocated footbath solutions after milking on 4 consecutive milkings each week, 2 wk, or monthly, depending on treatment. The footbath solutions were changed either after 200 cows had passed through the footbath or within $24 \mathrm{~h}$. All cows were scored weekly during milking for DD lesion stage on the hind feet using a 5-point nominal scale. A transition grade was assigned based on whether the DD lesions improved (1) or deteriorated or did not improve (0) from week to week, and was averaged for all cows in the group. Furthermore, from the longitudinal study data, all transitions between different DD lesion stages between the different time points were used in a discrete, first-order Markov chain (state transition matrix) model. In experiment 1, 70 Holstein-Friesian cows with DD lesions present on at least one of their hind feet were allocated to 1 of 2 footbath treatments for 14 wk: (1) $5 \% \mathrm{CuSO}_{4}$ each week or (2) $5 \% \mathrm{CuSO}_{4}$ every 2 wk. At the end of the study, no active DD lesions were observed in cows in either treatment group, but significantly more cows had no DD lesions $(0.48 \pm 0.097$ vs. $0.24 \pm 0.094)$ and fewer cows had lesions in the healing stage $(0.52 \pm 0.104$ vs. $0.77 \pm 0.090)$ for the weekly compared with the 2 -wk footbathing regimen. The number of active DD lesions that the transition matrix model predicted over time was 3 and $8 \%$ for weekly and every 2 wk footbathing treatments, respectively. In experiment 2, 64 cows with no DD lesions on either of their hind feet were allocated to 1 of 2 footbath treatment regimens for $14 \mathrm{wk}$ : (1) $5 \% \mathrm{CuSO}_{4}$ every 2 wk or (2) $5 \% \mathrm{CuSO}_{4}$ each month.

Received July 5, 2011.

Accepted February 2, 2012.

${ }^{1}$ Corresponding author: Mari.Speijers@afbini.gov.uk
At the end of the trial, significantly more cows had no DD $(0.80 \pm 0.088$ vs. $0.65 \pm 0.102)$ and fewer cows had DD lesions in the healing stage $(0.20 \pm 0.088$ vs. $0.35 \pm$ $0.102)$ in the every 2 wk regimen than in the monthly footbathing regimen. The number of active DD lesions that the transition matrix model predicted over time was low for both footbathing interventions ( 1 and $4 \%$, respectively). Increasing the interval between footbaths does not appear the most appropriate mechanism for reducing $\mathrm{CuSO}_{4}$ usage.

Key words: copper sulfate, dairy cow, digital dermatitis, footbathing frequency

\section{INTRODUCTION}

Lameness in dairy cows not only compromises the welfare of affected animals but has a detrimental effect on herd productivity. Digital dermatitis (DD) remains the main cause of infectious lameness and costs between $£ 76$ and $£ 84$ (US\$120 to 133 ) per case (Esslemont, 2005; Cha et al., 2010). Treatment cost was the main contributor to the total cost per case (Cha et al., 2010).

Digital dermatitis is caused by a spirochete infection, and it causes ulcerative lesions, inflammation, and skin damage, which cause pain and discomfort (Holzhauer et al., 2008a). The development of DD is related to damp, dirty underfoot conditions found in many freestall barns. In the last $30 \mathrm{yr}$, since DD was first reported, the disease has become a problem of epidemic proportions across continents, especially in those countries where cattle are housed for a significant part of the year (Laven and Logue, 2006). Regular footbathing of the cows is often viewed as an essential part of the prevention and control of DD (van Amstel and Shearer, 2006). A wide range of techniques, footbath solutions, frequencies, and management systems are used in the UK, despite publication of a guide for best practice for footbathing (DairyCo, 2009).

The solutions used in footbaths are largely influenced by farmer preference, but formalin and $\mathrm{CuSO}_{4}$, or a mixture of both, are the most commonly used solu- 
tions in the UK and the Netherlands (Holzhauer, 2006). Formalin is both toxic and carcinogenic (Speijers et al., 2010). Copper sulfate is widely available and relatively easy to use, and it is effective against DD when used as a footbath solution on a regular basis (Laven and Logue, 2006). Nevertheless, due to environmental concerns (Salam and El-Fadel, 2008) and with $42 \%$ of the total costs of DD due to treatment costs (Cha et al., 2010), it is imperative to maximize effectiveness and minimize waste in terms of $\mathrm{CuSO}_{4}$ footbath solution use.

Although footbathing strategies that feature long intervals between footbaths and reduce $\mathrm{CuSO}_{4}$ use need to be considered, little research has been done on the frequency of footbathing, and recommendations are tentative (Laven and Logue, 2006). In a previous study (Speijers et al., 2010), $\mathrm{CuSO}_{4}$ footbaths after milking on 4 consecutive milkings used every 2 wk were effective when prevalence of DD was relatively low (i.e., $\leq 25 \%$ ), but this regimen has not been investigated when the prevalence of DD is high. One of the aims of this study was to compare the effectiveness of weekly and $2 \mathrm{wk}$ footbathing in groups of cows with high prevalence of DD.

Furthermore, results from the previous study indicated that for groups of cows with low DD prevalence a 2-wk footbathing regimen could be used, and that the concentration of $\mathrm{CuSO}_{4}$ used could be reduced from $5 \%$ to $2 \%$ (Speijers et al., 2010). Therefore, a second aim was to investigate if the interval of time between footbath treatments could be increased to 1 mo for groups of cows with a very low prevalence of DD.

\section{MATERIALS AND METHODS}

\section{Animals and Management}

The study was conducted using the dairy herd at the Agri-Food and Biosciences Institute (Hillsborough, UK) during the winter housing period of 2009-2010. Animals were housed in freestalls with a concrete base fitted with rubber or pasture mats and bedded with sawdust 3 times weekly. The freestall to cow ratio was $\geq 1: 1$ at all times (Speijers et al., 2010). Solid concrete alleyway floors with occasional slats were scraped at least 4 times daily using an automated system. Cows were milked twice daily using a 50-stall rotary parlor. The cows used were also allocated to nutritional studies and a range of diets was fed. Overall, the concentrate to forage ratio (DM basis) varied from 60:40 to 20:80. The forage component was composed of 100 to $60 \%$ grass silage, with up to $40 \%$ corn silage.

All procedures used were conducted under the Animals (Scientific Procedures) Act, 1986, and with the permission and restrictions of the Agri-Food and Biosciences Institute (Hillsborough) Ethical Review Committee. As part of this, all animals in the herd were examined for lameness-causing conditions by an experienced stockperson on a regular basis, and feet were trimmed or treated (or both) when necessary. This information (i.e., diagnosis and treatment) was noted in the farm health records. For severe DD and other painful or contagious hoof problems (or both), evaluation entailed examination, claw trimming when appropriate, and topical treatment with a single application of antibiotic aerosol spray containing $2.45 \%$ (wt/ wt) chlortetracycline hydrochloride EP (Cyclo Spray, CEVA Animal Health Ltd., Chesham, UK). This application did not involve the use of a bandage.

\section{Footbathing Regimens and Solutions}

During the study period, the cows walked through the allocated footbath solution after milking on 4 consecutive milkings weekly $(\times \mathbf{4} / \mathbf{1} \mathbf{W}), 4$ consecutive times every $2 \mathrm{wk}(\times 4 / 2 \mathrm{~W})$, or 4 consecutive times monthly $(\times 4 / 4 \mathrm{~W})$ depending on their allocated treatment. Before walking through the footbath $\left(5 \% \mathrm{CuSO}_{4}\right)$, the cows walked through a prerinse footbath filled with water, according to good footbathing practice (DairyCo, 2009). The footbaths used were $207 \mathrm{~cm}$ long, $79 \mathrm{~cm}$ wide, and $22 \mathrm{~cm}$ high, and were filled to a volume of $270 \mathrm{~L}$. A distance of approximately $125 \mathrm{~cm}$ separated the prerinse and intervention footbaths.

The prerinse and treatment footbath solutions were changed either after 200 cows passed through the footbath or after $24 \mathrm{~h}$ if $<200$ cows had walked through in that period. Copper sulfate pentahydrate $25 \%$ (EPA Reg. no. 56576-1, DSM Nutritional Products UK Ltd., Belfast, UK) was used for the experimental footbath solution. To prepare the footbath solutions, each chemical was measured into a container before pouring it into the footbath and adding water to a depth of $16.5 \mathrm{~cm}$ (270 L) and mixing thoroughly.

\section{Experimental Treatments and Design}

Experiment 1. The experiment started in the first week of November 2009, when all cows in the herd had been housed (entirely or partially) for at least 2 wk. Lactating Holstein-Friesian cows $(\mathrm{n}=70)$ with DD lesions present on at least one of their hind feet during this 2 -wk housing period or immediately postcalving (high prevalence, HP cows) were selected from the herd and allocated to 1 of 2 treatments over a 14 -wk period: (1) footbathing $\times 4 / 1 \mathrm{~W}(\mathrm{n}=36)$ or $(2)$ footbathing $\times 4 / 2 \mathrm{~W}(\mathrm{n}=34)$. The cows were balanced as fully as possible across treatments (in order of priority) 
Table 1. Number of cows in the experimental treatments ${ }^{1}$ and their BW, numbers of lactations, DIM, and weekly milk yield at the start of the study (mean $\pm \mathrm{SE})$

\begin{tabular}{|c|c|c|c|c|c|c|}
\hline Item & $\mathrm{n}^{2}$ & BW (kg) & BCS & $\begin{array}{c}\text { Lactation } \\
\text { number }\end{array}$ & DIM & $\begin{array}{l}\text { Milk yield } \\
\quad(\mathrm{kg})\end{array}$ \\
\hline \multicolumn{7}{|l|}{ Experiment 1} \\
\hline $\mathrm{CuSO}_{4} 5 \%(\times 4 / 1 \mathrm{~W})$ & 29 & $614 \pm 16.8$ & $2.5 \pm 0.05$ & $2.7 \pm 0.25$ & $51 \pm 15.9$ & $30.3 \pm 1.85$ \\
\hline \multicolumn{7}{|l|}{ Experiment 2} \\
\hline $\mathrm{CuSO}_{4} 5 \%(\times 4 / 2 \mathrm{~W})$ & 26 & $571 \pm 14.5$ & $2.5 \pm 0.04$ & $2.2 \pm 0.26$ & $48 \pm 16.5$ & $28.4 \pm 2.15$ \\
\hline $\mathrm{CuSO}_{4} 5 \%(\times 4 / 4 \mathrm{~W})$ & 27 & $580 \pm 14.7$ & $2.4 \pm 0.03$ & $2.4 \pm 0.34$ & $63 \pm 20.7$ & $27.3 \pm 2.09$ \\
\hline
\end{tabular}

${ }^{1}$ Footbath treatments applied after 4 consecutive milkings weekly $(\times 4 / 1 \mathrm{~W})$, every $2 \mathrm{wk}(\times 4 / 2 \mathrm{~W})$, or monthly $(\times 4 / 4 \mathrm{~W})$.

${ }^{2}$ Excluding cows omitted from the study for various reasons (e.g., missing footbaths, ill health, or being culled or dying from causes unrelated to the study).

for ongoing nutritional treatment, parity, DIM, milk yield, worst digital dermatitis (DD) lesion score on either of the hind feet, BW, and BCS. The number of cows in the experimental treatments and their mean BW, number of lactations, DIM, and average milk yield at the start of the study (for this experiment and for experiment 2) are in Table 1. The management of the cows, other than the allocated footbathing treatments, remained unchanged (see Animals and Management Section), and these cows were not segregated from the rest of the herd.

Experiment 2. This experiment started at the same time as experiment 1 . Lactating cows $(\mathrm{n}=64)$ with no DD lesions on either of their hind feet at the start of the study [i.e., both "cured" and "possible resistant," hence called low prevalence $(\mathbf{L P})$ cows] were allocated to 1 of 2 footbathing regimens for 14 wk: (1) $\times 4 / 2 \mathrm{~W}$ footbathing with $5 \% \mathrm{CuSO}_{4}(\mathrm{n}=34)$ or $(2) \times 4 / 4 \mathrm{~W}$ footbathing with $5 \% \mathrm{CuSO}_{4}(\mathrm{n}=30)$. The animals were assigned and managed on the same basis as in experiment 1.

\section{Data Collection}

The same procedures for data collection were used in both experiments. Cows were examined in the milking parlor immediately after milking on a weekly basis. The hind feet were washed before examination using medium-pressure tap water. Dermatitis was scored on both hind feet of all animals using a 5-point nominal scale developed by Döpfer et al. (1997), which takes into account the stage of DD lesion development (Table 2). A flashlight was used to ensure adequate light for scoring. Number, size (greatest diameter of lesions to the nearest $0.5 \mathrm{~cm}$ ), color (red or not) of DD lesions, and presence of heel horn erosion on each hind foot were recorded. In cases where a hind foot had more than one lesion, the most active stage of DD lesion was recorded. All data were collected by 2 trained and experienced observers. The observers scored cows simultaneously on a few occasions and achieved substantial to almost-perfect agreement, with 83 to $94 \%$ agreement and kappa values of 0.71 to $0.89(\mathrm{n}=66$ to 114$)$.

\section{Statistical Analysis}

For the purpose of analysis, cows with early (M1) or acute classical ulcerative stage DD lesions (M2), or both (M1 + M2), on at least one hind foot were defined as having active DD lesions.

To determine the degree of healing, the transitions of DD lesions were defined as binomial data. For each cow that had DD lesions, the lesions were scored as "healed" when lesions were improving on both hind feet, and as "not healed" when one or both hind feet had lesions that were either getting worse or not improving from week to week. This grade was then used to obtain means for each treatment group. Improving lesions were defined as when lesion scores for a particular cow of M1 and M2 became M3 or M0. All other transitions between lesions stages, with the exception of M0 to M0 lesion score transitions, were defined as not improving

Table 2. Scoring system for classification of digital dermatitis (DD) lesions ${ }^{1}$

\begin{tabular}{ll}
\hline DD score & Description \\
\hline M0 & No lesion \\
M1 & Early stage lesion up to $2 \mathrm{~cm}$ in diameter; generally not painful \\
M2 & Classical ulcerative stage with a diameter greater than $2 \mathrm{~cm}$; often very painful upon touch \\
M3 & Healing stage whereby the lesion is covered by a scab \\
M4 & Chronic stage of lesion, characterized by dyskeratosis or proliferation of the surface; generally not painful upon touch \\
\hline
\end{tabular}

${ }^{1}$ Developed by Döpfer et al. (1997). 
or getting worse (i.e., not healed). Lesion score transitions from M0 to M0 between 2 consecutive weeks were excluded from healing analysis, and these occurrences were analyzed separately.

Nine cows (experiment 1) and 11 cows (experiment 2) were omitted from the analysis for a range of reasons, which included missing footbaths, ill health, or being culled or dying from causes unrelated to the study.

All statistical analyses were carried out using the statistical package GenStat 12 (2009; VSN International Ltd., Hemel Hempstead, UK). The effect of the treatment regimens on the proportion of cows with different DD lesion stages, and on healing rates, during the experimental period was assessed using General Estimating Equation (GEE) analysis with a binomial error distribution and an ante-dependence covariance structure of 1 between the time points (weeks). Data are presented as means \pm standard error of the difference (SED) unless otherwise stated. Significance is represented using $P<0.05$. Percentages of cows with active lesions for the different treatments are presented graphically.

From the longitudinal study data, the number of cows in each of the different DD stages at any given time and the transitions between the different DD lesion stages between the different time points (i.e., weeks) were determined and used to calculate the transition probabilities. The transition probabilities were arranged in a transition matrix for each treatment group. This matrix was then used in a discrete, first-order Markov chain (state transition) model, where the relevant parameters are the transition probabilities (Zipkin et al., 2010). The Markov chain methodology combines all states and transition probabilities in sub-events, which are then combined to predict the probability of the top-level event (stationary probabilities) when equilibrium is reached. In other words, the model predicts the relative prevalence of the DD lesion stages after a long period (Döpfer et al., 2008).

\section{RESULTS}

\section{Foot Health and Characteristics of Lesions}

Twelve cows were sufficiently lame that they were fully examined, trimmed if appropriate, and received topical treatment (antibiotic aerosol spray) for a range of feet and leg problems. Of these animals, only 4 were treated for severe DD lesions during the experimental period. The remaining 8 experimental cows that received treatment had no DD before or after treatment and were treated for other reasons. The number of topical treatments received was very low relative to the overall occurrences of DD lesions. Therefore, the overall effect of these topical treatments on occurrence and presentation of DD during the experimental period was considered minimal and ignored.

Most DD lesions were a single lesion of each foot $(99.9 \%)$, and most cows with lesions had lesions on both hind feet (63\%). The size of an early stage lesion (M1) was $1.0 \pm 0.16 \mathrm{~cm}$ and that of an acute classical ulcerative stage (M2) was $3.1 \pm 0.10 \mathrm{~cm}$. The average size of a healing (M3) lesion was $1.6 \pm 0.03 \mathrm{~cm}$. No M4 lesions were observed.

Experiment 1. The distributions of the different DD lesion stages for the HP cows for the different footbathing treatments at the start and end of the trial are in Table 3. At the start of the trial, the treatments did not differ in the overall presence of active DD lesions (M1 and M2), and the proportion of cows with M3 lesions was higher for the $\times 4 / 1 \mathrm{~W}$ compared with the $\times 4 / 2 \mathrm{~W}$ regimen. These differences between the treatments for the separate DD lesion stages (M1 to M3) were due to the necessity of allocating the cows to footbathing intervention on the basis of their worst DD score $(\mathrm{M} 2>\mathrm{M} 1>\mathrm{M} 3)$ on either of their hind feet. At the end of the study period, no active DD lesions were observed in either footbathing regimen, but more cows had no DD lesions and fewer cows had lesions in the healing stage (M3) for the $\times 4 / 1 \mathrm{~W}$ compared with the $\times 4 / 2 \mathrm{~W}$ regimen $(P<0.001)$. The average diameter of acute classical ulcerative stage lesions (M2) for cows on the $\times 4 / 2 \mathrm{~W}$ footbathing regimen was more than $0.5 \mathrm{~cm}$ larger than that for the cows on the $\times 4 / 1 \mathrm{~W}$ footbathing regimen $(3.4 \pm 0.14$ vs. $2.8 \pm 0.14 \mathrm{~cm})$.

The proportion of cows that had DD lesions following normal healing transitions was similar for both footbathing regimens $(0.76$ and 0.70 for $\times 4 / 1 \mathrm{~W}$ and $\times 4 / 2 \mathrm{~W}$ interventions, respectively; $\mathrm{SED}=0.057 ; P>$ $0.05)$. We found no treatment difference for the proportion of cows with M0 to M0 lesion transitions between 2 consecutive weeks, with $0.11 \pm 0.036$ for both footbathing regimens over the experimental period $(P>0.05)$.

The number of cows with active lesions (M1 and M2) over the experimental period for the different footbathing regimens are in Figure 1. The number of cows with active DD lesions decreased steadily for both interventions over the study period $(P=0.002$ and $P=$ 0.004 for the $\times 4 / 1 \mathrm{~W}$ and $\times 4 / 2 \mathrm{~W}$ footbathing regimen, respectively), but we observed "flare-ups" (sawtooth pattern) of active DD lesions in wk 2, 4, 6, 8, and 10 (Figure 1). On these occasions, the prevalence of DD was higher in the $\times 4 / 2 \mathrm{~W}$ footbathing regimen than in the $\times 4 / 1 \mathrm{~W}$ footbathing regimen $(P<0.001)$.

In total, 619 and 651 transitions between the different DD lesion stages during the experimental period were recorded for the weekly and every 2 wk footbathing regimens, respectively. The probabilities for 
Table 3. Proportional distribution of digital dermatitis (DD) lesion scores in the hind feet of cows with high DD prevalence (HP) at the start of experiment 1 for weekly and every 2 wk footbathing treatment regimens (5\% $\mathrm{CuSO}_{4}$ footbaths on 4 consecutive occasions)

\begin{tabular}{llccc}
\hline DD stage & Period & $\begin{array}{c}\text { HP weekly } \\
(\mathrm{n}=29)\end{array}$ & $\begin{array}{c}\text { HP every 2 wk } \\
(\mathrm{n}=32)\end{array}$ & SED \\
\hline M0 (no lesion) & Start & 0.08 & 0.02 & 0.036 \\
& End & $0.48^{\mathrm{b}}$ & $0.24^{\mathrm{a}}$ & 0.036 \\
M1 (active) & Start & 0.04 & 0.04 & 0.005 \\
& End & 0.00 & 0.01 & 0.005 \\
M2 (active) & Start & 0.42 & 0.45 & 0.021 \\
& End & 0.00 & 0.01 & 0.021 \\
M3 (healing) & Start & $0.67^{\mathrm{b}}$ & $0.53^{\mathrm{a}}$ & 0.037 \\
& End & $0.52^{\mathrm{a}}$ & $0.77^{\mathrm{b}}$ & 0.037 \\
\hline
\end{tabular}

$\overline{\mathrm{a}, \mathrm{b}}$ Means within a row with different superscripts differ $(P<0.05)$.

${ }^{1} \mathrm{DD}$ stage M0 in both hind feet and DD stage M1 to M3 in at least one hind foot.

transition between the different DD lesion stages were similar for both footbathing regimens (Tables 4 and $5)$. Both interventions showed that when a cow had an acute classical ulcerative DD lesion stage (M2), the probability that the lesions would remain in this stage at the next scoring date was 0.24 to 0.26 (Tables 4 and 5). Although the number of active DD lesions that the transition matrix model predicted over time was low for both treatments, it was higher for every $2 \mathrm{wk}$ regimen compared with the weekly regimen ( 8 vs. $3 \%$, respectively; Tables 4 and 5).

Experiment 2. The distributions of the different DD lesion stages on both feet of the LP cows for the different footbathing regimens at the start and end of the trial are in Table 6. As per allocation, no DD lesions were present at the start of the trial. At the end of the trial, more cows had no DD and fewer cows had healing DD lesions in the $\times 4 / 2 \mathrm{~W}$ than in the $\times 4 / 4 \mathrm{~W}$ footbathing regimen $(P<0.05)$.

Treatment had no effect on overall healing transitions of DD lesions; the proportion of cows that had DD lesions following normal healing transition was 0.59 and 0.51 for the $\times 4 / 2 \mathrm{~W}$ and $\times 4 / 4 \mathrm{~W}$ footbathing regimens, respectively $(\mathrm{SED}=0.044 ; P>0.05)$. Treatment had no effect on the proportion of cows with M0 to M0 lesion transitions between 2 consecutive weeks, with values of 0.53 and 0.48 for the $\times 4 / 2 \mathrm{~W}$ and $\times 4 / 4 \mathrm{~W}$ footbathing regimens, respectively $(\mathrm{SED}=0.036 ; P>$ $0.05)$.

In total, 582 and 592 transitions between the different DD lesion stages during the experimental period were recorded for the $2 \mathrm{wk}$ and monthly footbathing

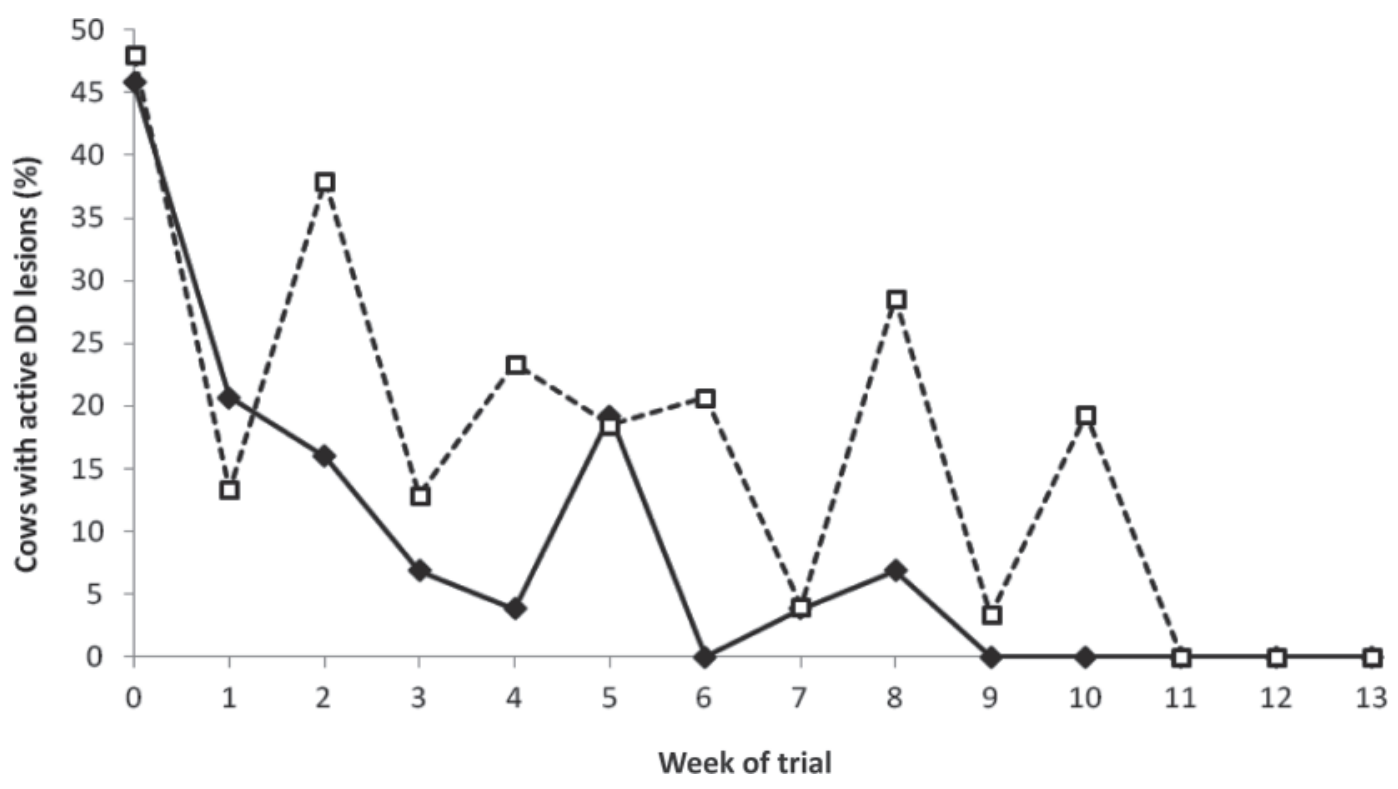

Figure 1. Experiment 1: percentage of cows with active digital dermatitis (DD) lesions (a DD lesion score of M1 or M2 in at least one hind foot) for weekly $(--; \mathrm{n}=29)$ or every $2 \mathrm{wk}(--\square--; \mathrm{n}=32)$ footbathing with $5 \% \mathrm{CuSO}_{4}$ over the experimental period. 
Table 4. Probabilities for transitions $(\mathrm{n}=619)$ between digital dermatitis (DD) lesion stages ${ }^{1}$ for cows with high DD prevalence at the start of experiment 1 on the weekly footbathing regimen $\left(5 \% \mathrm{CuSO}_{4}\right.$ footbaths on 4 consecutive occasions)

\begin{tabular}{|c|c|c|c|c|}
\hline \multirow[b]{2}{*}{ Lesion $t_{2}$} & \multicolumn{4}{|c|}{ Lesion $t_{1}{ }^{2}$} \\
\hline & M0 & M1 & M2 & M3 \\
\hline M0 & 0.68 & 0.00 & 0.11 & 0.17 \\
\hline M1 & 0.00 & 0.00 & 0.00 & 0.00 \\
\hline M2 & 0.02 & 0.00 & 0.24 & 0.03 \\
\hline M3 & 0.30 & 1.00 & 0.65 & 0.79 \\
\hline Number of transitions & 186 & 1 & 37 & 395 \\
\hline Number of lesions at start (proportion) ${ }^{2}$ & 0.31 & 0.00 & 0.06 & 0.63 \\
\hline Predicted relative prevalence $^{3}$ & 0.35 & 0.00 & 0.03 & 0.62 \\
\hline
\end{tabular}

regimens, respectively. The probabilities for transition between the different DD lesion stages were mostly similar for both footbathing regimens (Tables 7 and 8). We observed a difference between the treatments in the probability of transitions between DD lesion stages from when a cow had an acute classical ulcerative DD lesion stage (M2) on the previous scoring date. When the DD lesion stage classes were combined into active or nonactive DD lesion stage, the 2 regimens did not differ. The number of active DD lesions that the transition matrix model predicted over time was very low for both footbathing regimens (Tables 7 and 8).

The active DD lesions (M1 and M2) over the experimental period for the treatments are in Figure 2. In both treatments, we observed "flare-ups" (sawtooth pattern) of active DD lesions in wk 2, 7, and 10 for $\times 4 / 4 \mathrm{~W}$ group and in wk 5 for the $4 / 2 \mathrm{~W}$ regimen (Figure 2); on these occasions, the prevalence of DD was higher compared with the other footbathing treatment $(P<0.001$ for wk 2, 5 and 7 , and $P<0.05$ for wk 10).

\section{DISCUSSION}

At the start of the current study, after being housed for $2 \mathrm{wk}, 20 \%$ of the cows were affected by active DD lesions (M1 and M2) on at least one of their hind feet. Dutch and Danish surveys found a mean DD prevalence of 20\% in infected herds (Holzhauer et al., 2006; Capion et al., 2008). At this prevalence, DD is an endemic herd problem and preventative herd intervention is required (Berry et al., 1999; Zemljic, 2008). This is essential to avoid the risk of spreading infection to other cows due to persisting microorganisms (Mumba et al., 1999). For example, without preventive herd strategies, the baseline for active infection of the herd is 5 to $6 \% / \mathrm{wk}$ (Holzhauer et al., 2008a; Speijers et al., 2010), highlighting the importance of routine footbathing.

At present, scientific information is lacking on the best regimens for dairy cows in terms of frequency of nonantibiotic footbath use (Laven and Logue, 2006). The general advice is that the frequency of footbathing

Table 5. Probabilities for transitions $(\mathrm{n}=651)$ between digital dermatitis $(\mathrm{DD})$ lesion stages ${ }^{1}$ for cows with high DD prevalence at the start of experiment 1 on the every 2 wk footbathing regimen $\left(5 \% \mathrm{CuSO}_{4}\right.$ footbaths on 4 consecutive occasions)

\begin{tabular}{lcccc}
\hline & \multicolumn{4}{c}{ Lesion ${ }^{2}$} \\
\cline { 2 - 5 } Lesion $\mathrm{t}_{2}$ & $\mathrm{M} 0$ & $\mathrm{M} 1$ & $\mathrm{M} 2$ & $\mathrm{M} 3$ \\
\hline M0 & 0.63 & 0.00 & 0.00 & 0.16 \\
M1 & 0.01 & 0.00 & 0.00 & 0.00 \\
M2 & 0.01 & 0.00 & 0.26 & 0.08 \\
M3 & 0.35 & 1.00 & 0.74 & 0.76 \\
Number of transitions & 175 & 2 & 69 & 405 \\
Number of lesions at start (proportion) & 0.27 & 0.00 & 0.11 & 0.61 \\
Predicted relative prevalence & 0.27 & 0.00 & 0.08 & 0.65 \\
\hline
\end{tabular}

${ }^{1} \mathrm{DD}$ lesion stages: $\mathrm{M} 0=$ no lesion; $\mathrm{M} 1=$ early active lesion; $\mathrm{M} 2=$ ulcerative active lesion; $\mathrm{M} 3=$ healing lesion. ${ }^{2}$ Lesion $t_{1}$ and $t_{2}$ indicate time points, where lesion $t_{1}$ is the DD stage in one week and lesion $t_{2}$ is the DD stage in the subsequent week.

${ }^{3}$ Stationary probabilities. 
Table 6. Proportional distribution of digital dermatitis (DD) lesion scores in hind feet in cows with no DD lesions on either foot (low prevalence, LP) at the start of experiment 2 for every 2 wk and monthly footbathing treatment regimens $\left(5 \% \mathrm{CuSO}_{4}\right.$ footbaths on 4 consecutive occasions)

\begin{tabular}{llccc}
\hline DD stage $^{1}$ & Period & $\begin{array}{c}\text { LP every } 2 \text { wk } \\
(\mathrm{n}=26)\end{array}$ & $\begin{array}{c}\text { LP monthly } \\
(\mathrm{n}=27)\end{array}$ & SED \\
\hline M0 (no lesion) & Start & 1.00 & 1.00 & 0.036 \\
& End & $0.80^{\mathrm{b}}$ & $0.65^{\mathrm{a}}$ & 0.036 \\
M1 (active) & Start & 0.00 & 0.00 & 0.005 \\
& End & 0.00 & 0.00 & 0.005 \\
M2 (active) & Start & 0.00 & 0.00 & 0.020 \\
M3 (healing) & End & 0.00 & 0.00 & 0.020 \\
& Start & 0.00 & 0.00 & 0.037 \\
\end{tabular}

${ }^{\mathrm{a}, \mathrm{b}}$ Means within a row with different superscripts differ $(P<0.05)$.

${ }^{1} \mathrm{DD}$ stage M0 in both hind feet and DD stage M1 to M3 in at least one hind foot.

should be determined by the prevalence of DD within the herd (DairyCo, 2009). The frequency of footbathing can vary from $1 / \mathrm{d}$ to less than once every 2 wk on commercial farms (Sumner and Davies, 1984). In practice, footbathing frequency appears to be determined as much by farmers' judgments and practicalities such as site of footbath and ease of filling and emptying [J. Offer, Scottish Agricultural College (SAC), Riverside Campus, Ayr, UK, unpublished data] as by the DD challenge.

The size of acute classical ulcerative stage lesions (M2) was smaller for the weekly regimen compared with the every 2 wk regimen ( 2.8 vs. $3.4 \mathrm{~cm})$. Larger lesion size is associated with increased presence of spirochetes, which are implicated in the etiology of DD (Mumba et al., 1999; Elliott et al., 2007), and lower healing rates (Shahabaddin et al., 2007; Nishikawa and Taguchi, 2008). Holzhauer et al. (2008b) found that both weekly and every $2 \mathrm{wk}$ regimens were effective in preventing a serious outbreak of DD (i.e., $>30 \%$ of hind legs with M2 lesions), but that a weekly footbathing (twice on 1 d) regimen with $4 \%$ formalin was more effective than a
2 -wk regimen. The results of the present study suggest that in a group of cows where the prevalence of DD is high, the best practice is to use a weekly, rather than every $2 \mathrm{wk}, 5 \% \mathrm{CuSO}_{4}$ footbathing routine.

During the study, new and recurring DD infections occurred despite treatments. This supports other findings that DD can be controlled maximally but not eliminated (Laven and Logue, 2006). Obtaining a complete resolution of DD within the herd has been difficult, and a high recurrence rate can exist after topical (Read and Walker, 1998; Mumba et al., 1999; Berry et al., 2010) or other treatment (Holzhauer et al., 2008b).

In experiment 2, neither footbathing regimen tested in the LP group prevented DD infection occurring (or recurring) during the study period. Under the current experimental design, the groups of cows could not be separately managed. Therefore, it was possible for infection to be transmitted from other infected cows to these cows (LP). Another explanation for the occurrences of DD infection in the LP cow group could be that at allocation, despite no clinical presentation of the disease, the cows carried infection in the deeper

Table 7. Probabilities for transitions $(\mathrm{n}=582)$ between digital dermatitis (DD) lesion stages ${ }^{1}$ for cows with no DD lesions on either foot at the start of experiment 2 on the every 2 wk footbathing regimen $\left(5 \% \mathrm{CuSO}_{4}\right.$ footbaths on 4 consecutive occasions)

\begin{tabular}{lcccc}
\hline & \multicolumn{4}{c}{ Lesion $_{1}{ }^{2}$} \\
\cline { 2 - 5 } Lesion $t_{2}$ & M0 & M1 & M2 & M3 \\
\hline M0 & 0.86 & 0.33 & 0.14 & 0.45 \\
M1 & 0.00 & 0.00 & 0.14 & 0.01 \\
M2 & 0.00 & 0.33 & 0.29 & 0.02 \\
M3 & 0.14 & 0.33 & 0.43 & 0.53 \\
Number of transitions & 447 & 3 & 7 & 125 \\
Number of lesions at start (proportion) & 0.77 & 0.00 & 0.01 & 0.21 \\
Predicted relative prevalence & 0.76 & 0.00 & 0.01 & 0.23 \\
\hline
\end{tabular}

${ }^{1} \mathrm{DD}$ lesion stages: $\mathrm{M} 0=$ no lesion; $\mathrm{M} 1=$ early active lesion; $\mathrm{M} 2=$ ulcerative active lesion; M3 = healing lesion. ${ }^{2}$ Lesion $t_{1}$ and $t_{2}$ indicate time points, where lesion $t_{1}$ is the DD stage in one week and lesion $t_{2}$ is the DD stage in the subsequent week.

${ }^{3}$ Stationary probabilities. 
Table 8. Probabilities for transitions $(\mathrm{n}=592)$ between digital dermatitis (DD) lesion stages ${ }^{1}$ for cows with no DD lesions on either foot at the start of experiment 2 on the monthly footbathing regimen $\left(5 \% \mathrm{CuSO}_{4}\right.$ footbaths on 4 consecutive occasions)

\begin{tabular}{|c|c|c|c|c|}
\hline \multirow[b]{2}{*}{ Lesion $t_{2}$} & \multicolumn{4}{|c|}{ Lesion $t_{1}{ }^{2}$} \\
\hline & M0 & M1 & M2 & M3 \\
\hline M0 & 0.82 & 0.00 & 0.25 & 0.44 \\
\hline M1 & 0.00 & 0.00 & 0.00 & 0.00 \\
\hline M2 & 0.01 & 0.00 & 0.45 & 0.07 \\
\hline M3 & 0.17 & 0.00 & 0.30 & 0.49 \\
\hline Number of transitions & 441 & - & 20 & 131 \\
\hline Number of lesions at start (proportion) & 0.73 & 0.00 & 0.04 & 0.23 \\
\hline Predicted relative prevalence & 0.70 & 0.00 & 0.04 & 0.26 \\
\hline
\end{tabular}

${ }^{1} \mathrm{DD}$ lesion stages: $\mathrm{M} 0=$ no lesion; $\mathrm{M} 1=$ early active lesion; $\mathrm{M} 2=$ ulcerative active lesion; $\mathrm{M} 3=$ healing lesion. ${ }^{2}$ Lesion $t_{1}$ and $t_{2}$ indicate time points, where lesion $t_{1}$ is the DD stage in one week and lesion $t_{2}$ is the DD stage in the subsequent week.

${ }^{3}$ Stationary probabilities.

skin tissues (Dhawi et al., 2005; Nordhoff et al., 2008; Evans et al., 2009). Thus, although it is reasonable to argue that some of the cows in experiment 2 were resistant to infection, this would not necessarily apply to all, and does not invalidate our argument that if the disease is initially controlled by weekly footbathing, it may be possible to move to treatment every 2 wk without a great loss of effectiveness.

It is interesting to note that, despite the occurrences of new infections, the prevalence of active DD lesions in LP cows never exceeded $13 \%$ for both footbathing regimens. We hypothesize that this figure would have been lower if these cows were managed separately from the HP cows, thus minimizing contact with infectious reservoirs. More in-depth research is required to quantify these causal factors.
When comparing the every 2 wk and monthly footbathing regimens in the LP group, the healing rate of DD was similar, and all DD lesions had healed for both footbathing regimens at the end of the experiment. This suggests that both interventions helped control the spread of DD. Similarly, a survey of 12 commercial farms in the Netherlands found that biweekly or monthly footbathing with nonantibiotic solutions did not change the incidences of DD over a period of 22 wk, but full protocols, number of farms using $\mathrm{CuSO}_{4}$, and concentrations of solutions used were not specified (Somers et al., 2005).

In the current study, the DD recording system was used to collect ordinal data, which took into account various stages of the disease. The GEE analysis used was based on a binomial distribution; that is, the pres-

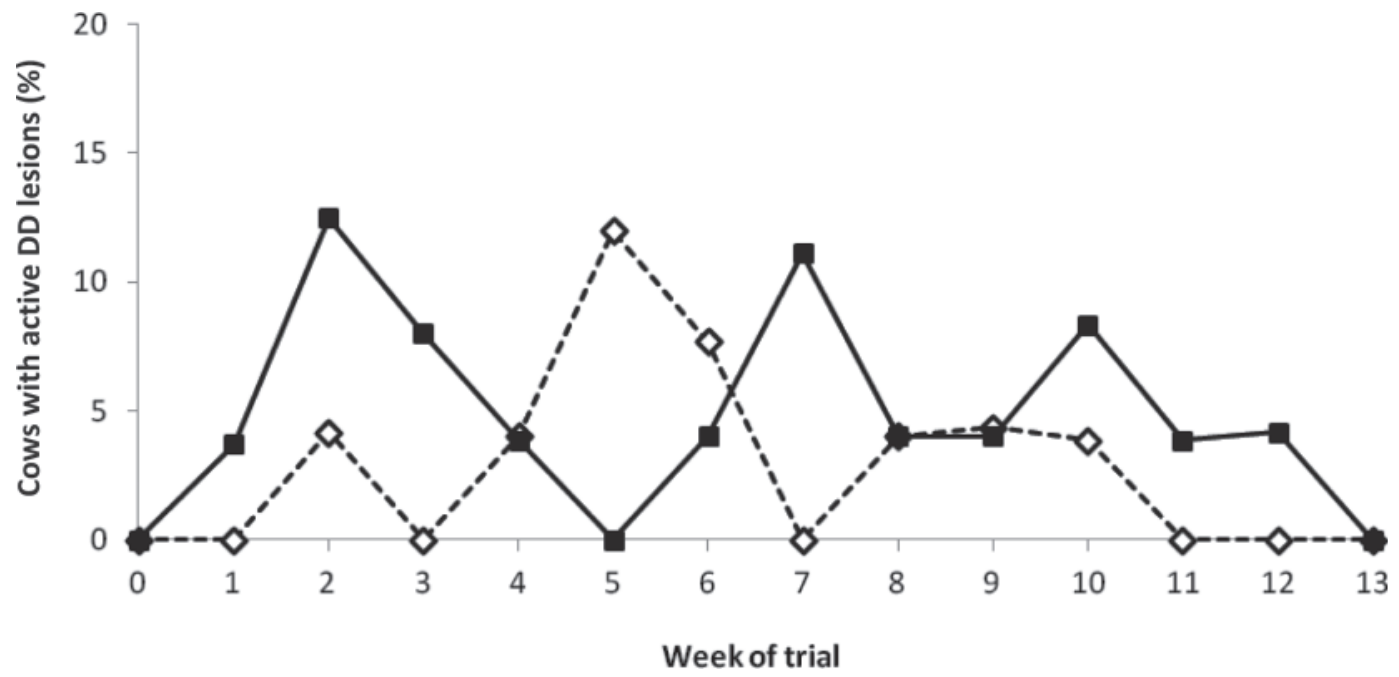

Figure 2. Experiment 2: percentage of cows with active digital dermatitis (DD) lesions (a DD lesion score of M1 or M2 in at least one hind foot) for every $2 \mathrm{wk}\left(\times 4 / 2 \mathrm{~W},---_{--} ; \mathrm{n}=26\right)$ or monthly $(\times 4 / 4 \mathrm{~W},-\boldsymbol{-}-; \mathrm{n}=27)$ footbathing with $5 \% \mathrm{CuSO}_{4}$ over the experimental period. 
ence or absence of a particular DD lesion stage or combination of DD lesion stages for each time point (week), with an ante-dependence covariance structure of 1 between the time points. Another way of looking at the longitudinal study data is to use a discrete, first-order Markov chain (state transition) model. These models are powerful tools applicable to the study of disease dynamics that allow straightforward calculations of easily interpretable metrics of interest including probabilities of infection, recovery, or both (Zipkin et al., 2010). Döpfer et al. (2008) concluded that a transition matrix model was an invaluable tool to gain insight into the relative frequencies of transitions between stages of DD lesions and to evaluate long-term effect of DD interventions. In the current study, the Markov chain model predicted that over time there were more healthy feet (6 to $8 \%$ ) and fewer active DD lesions (3 to 5\%) in the more frequent footbathing regimen tested in both the HP and LP groups of cows, suggesting that these regimens are more effective in controlling DD.

Approximately half of the cows in the LP group did not develop DD lesions during the experimental period, irrespective of treatment, presumably because of some form of resistance to the infection, although not necessarily freedom from it. This is supported by the Markov chain model predicting that even after "unlimited" time, the majority of cows would remain free of DD lesions. This supports Somers et al. (2005), who found that the majority of hind feet that had no DD lesions at the start of their study remained healthy throughout a 5-mo period. Furthermore, Laven and Logue (2007) found that, in heifers in a high-risk environment, the absence of DD before calving was related to low DD prevalence after calving. Laven (1999) reported that 20 to $25 \%$ of cows appear resistant to DD infection. In the current study, no DD scoring was carried out before calving for comparison, but the results do indicate that other factors are involved besides disease challenge and treatment per se, and suggest that individual cow differences may affect susceptibility to DD. Further research is needed to explain the variation in the way cows are affected by DD and respond to DD interventions.

\section{CONCLUSIONS}

Increasing the interval between footbathing sessions with $5 \% \mathrm{CuSO}_{4}$ is not without risk for new, painful DD infections and does not appear the most appropriate mechanism for reducing $\mathrm{CuSO}_{4}$ usage and maintaining its effectiveness. Future research should concentrate on investigating alternatives to $\mathrm{CuSO}_{4}$ solutions. This study highlighted the importance of regular footbathing to control DD, in addition to regular monitoring of the disease.

\section{ACKNOWLEDGMENTS}

The authors are indebted to technicians and stockmen in the Dairy Unit of the Agri-Food and Biosciences Institute (Hillsborough, UK) for their excellent technical assistance and care of the animals. The authors gratefully acknowledge AgriSearch and the Department of Agriculture and Rural Development (DARD) for Northern Ireland for funding this project.

\section{REFERENCES}

Berry, S. L., D. H. Read, and R. L. Walker. 1999. Recurrence of PDD in dairy cows after treatment with lincomycin $\mathrm{HCl}$ or oxytetracycline HCl. J. Dairy Sci. 82:S34. (Abstr.)

Berry, S. L., D. H. Read, R. L. Walker, and T. R. Famula. 2010. Clinical, histologic, and bacteriologic findings in dairy cows with digital dermatitis (footwarts) one month after topical treatment with lincomycin hydrochloride or oxytetracycline hydrochloride. J. Am. Vet. Med. Assoc. 237:555-560.

Capion, N., S. M. Thamsborg, and C. Enevoldsen. 2008. Prevalence of foot lesions in Danish Holstein cows. Vet. Rec. 163:80-85.

Cha, E., J. A. Hertl, D. Bar, and Y. T. Grohn. 2010. The cost of different types of lameness in dairy cows calculated by dynamic programming. Prev. Vet. Med. 97:1-8.

DairyCo. 2009. Footbathing and Lameness: Effective Management for Dairy Cows. DairyCo, Cirencester, UK.

Dhawi, A., C. A. Hart, I. Demirkan, I. H. Davies, and S. D. Carter. 2005. Bovine digital dermatitis and severe virulent ovine foot rot: A common spirochaetal pathogenesis. Vet. J. 169:232-241.

Döpfer, D., M. G. Lopez Benavides, T. Hemling, G. Cavalcanti, and W. Ingalls. 2008. A transition matrix model to evaluate the effect of a walk-through hoofbath used to cure and prevent digital dermatitis in a class-structured population of dairy cows. Pages 183-185 in Proc. 15th Int. Symp. 7th Conf. Lameness in Ruminants, Kuopio, Finland. Savonia University of Applied Sciences, Kuopio, Finland.

Döpfer, D., A. A. H. M. ter Huurne, J. L. Cornelisse, A. J. A. M. van Asten, A. Koopmans, F. A. Meijer, Y. H. Schukken, I. Szakall, W. Klee, and R. B. Bosma. 1997. Histological and bacteriological evaluation of digital dermatitis in cattle, with special reference to spirochaetes and Campylobacter faecalis. Vet. Rec. 140:620-623.

Elliott, M. K., D. P. Alt, and R. L. Zuerner. 2007. Lesion formation and antibody response induced by papillomatous digital dermatitis-associated spirochetes in a murine abscess model. Infect. Immun. 75:4400-4408.

Esslemont, R. J. 2005. The costs of lameness in dairy herds. UK Vet. Livest. 10:41-49.

Evans, N. J., J. M. Brown, I. Demirkan, S. Prem, B. Getty, D. Timofte, W. D. Vink, R. D. Murray, R. W. Blowey, R. J. Birtles, C. A. Hart, and S. D. Carter. 2009. Association of unique, isolated treponemes with bovine digital dermatitis lesions. J. Clin. Microbiol. 47:689-696.

Holzhauer, M. 2006. Gebruik van kopersulfaat in de praktijk en mogelijke alternatieven. Pages 22-24 in Gebruik van kopersulfaat in voetbaden-De overschotten lopen uit de klauwen. M. Boer, A. Kool, and F. v. d. Schans, ed. CLM Onderzoek en Advies BV, Culemborg, the Netherlands.

Holzhauer, M., C. J. M. Bartels, D. Döpfer, and G. van Schaik. 2008a. Clinical course of digital dermatitis lesions in an endemically infected herd without preventive herd strategies. Vet. J. 177:222230.

Holzhauer, M., D. Döpfer, J. De Boer, and G. Van Schaik. 2008b. Effects of different intervention strategies on the incidence of papillomatous digital dermatitis in dairy cows. Vet. Rec. 162:41-46.

Holzhauer, M., C. Hardenberg, C. J. M. Bartels, and K. Frankena. 2006. Herd- and cow-level prevalence of digital dermatitis in the Netherlands and associated factors. J. Dairy Sci. 89:580-588. 
Laven, R. A. 1999. The environment and digital dermatitis. Cattle Pract. 7:349-354.

Laven, R. A., and D. N. Logue. 2006. Treatment strategies for digital dermatitis for the UK. Vet. J. 171:79-88.

Laven, R. A., and D. N. Logue. 2007. The effect of pre-calving environment on the development of digital dermatitis in first lactation heifers. Vet. J. 174:310-315.

Mumba, T., D. Döpfer, C. Kruitwagen, M. Dreher, W. Gaastra, and B. A. M. van der Zeijst. 1999. Detection of spirochetes by polymerase chain reaction and its relation to the course of digital dermatitis after local antibiotic treatment in dairy cattle. Zentralbl. Veterinarmed. B 46:117-126.

Nishikawa, A., and K. Taguchi. 2008. Healing of digital dermatitis after a single treatment with topical oxytetracycline in 89 dairy cows. Vet. Rec. 163:574-576.

Nordhoff, M., A. Moter, K. Schrank, and L. H. Wieler. 2008. High prevalence of treponemes in bovine digital dermatitis - A molecular epidemiology. Vet. Microbiol. 131:293-300.

Read, D. H., and R. L. Walker. 1998. Papillomatous digital dermatitis (footwarts) in California dairy cattle: Clinical and gross pathologic findings. J. Vet. Diagn. Invest. 10:67-76.

Salam, D., and M. El-Fadel. 2008. Mobility and availability of copper in agricultural soils irrigated from water treated with copper sulfate algaecide. Water Air Soil Pollut. 195:3-13.
Shahabaddin, M., I. Nowrouzian, M. Nouri, and S. M. K. S. Javad. 2007. Clinical assessment of four individual treatment for digital dermatitis in dairy cows. Iran. J. Vet. Surg. 2:56-61.

Somers, J. G. C. J., W. G. P. Schouten, K. Frankena, E. N. Noordhuizen-Stassen, and J. H. M. Metz. 2005. Development of claw traits and claw lesions in dairy cows kept on different floor systems. J. Dairy Sci. 88:110-120.

Speijers, M. H. M., L. G. Baird, G. A. Finney, J. McBride, D. J. Kilpatrick, D. N. Logue, and N. E. O'Connell. 2010. Effectiveness of different footbath solutions in the treatment of digital dermatitis in dairy cows. J. Dairy Sci. 93:5782-5791.

Sumner, J., and R. C. Davies. 1984. Footbaths on dairy farms in England and Wales. Vet. Rec. 114:88.

van Amstel, S. R., and J. K. Shearer. 2006. Manual for Treatment and Control of Lameness in Cattle. 1st ed. Blackwell Publishing, Oxford, UK.

Zemljic, B. 2008. Are there any possibilities to eliminate digital dermatitis from dairy herd? Pages 304-306 in Proc. Int. Symp. Lameness in Ruminants, Kuopio, Finland. Savonia University of Applied Sciences, Kuopio, Finland.

Zipkin, E. F., C. S. Jenelle, and E. G. Cooch. 2010. A primer on the application of Markov chains to the study of wildlife disease dynamics. Method Ecol. Evol. 1:192-198. 